\title{
Crescimento inicial de Acácia em condicionador formado de fibra de coco e resíduo agregante ${ }^{1}$
}

\author{
Rômulo F. Duarte ${ }^{1}$, Regynaldo A. Sampaio ${ }^{2}$, Delacyr da S. Brandão Júnior ${ }^{3}$, Luiz A. Fernandes ${ }^{3} \&$ Humberto P. da Silva $^{4}$
}

\section{RESUMO}

Propôs-se, neste trabalho, avaliar manta (condicionador do solo) formada de fibra de coco e resíduo agregante com diferentes substratos no crescimento inicial de plantas de Acacia mangium W illd. Utilizou-se o delineamento de blocos ao acaso, com 13 tratamentos e três repetições, distribuídos em esquema fatorial $(6 \times 2+1)$, sendo 6 proporções de fibra de coco e resíduo agregante (100 e 0\%, 90 e 10\%, 80 e 20\%, 70 e 30\%, 60 e 40\%, 50 e 50\%), 2 substratos contendo lodo de esgoto (terra de subsolo de Latossolo Vermelho-Amarelo (LVA) + lodo de esgoto na proporção 2:1) e esterco bovino (terra de subsolo de Latossolo Vermelho-A marelo (LVA) + esterco bovino curtido na relação 3:1), e a testemunha como tratamento adicional, terra de subsolo de Latossolo Vermelho-Amarelo (LVA). Após 173 dias da semeadura a manta, contendo LVA + esterco bovino curtido (3:1), foi superior ao substrato com terra de subsolo de LVA e lodo de esgoto (2:1) no desenvolvimento inicial de A. mangium Willd em altura e comprimento da raiz. Mantas contendo aproximadamente de 90 a $100 \%$ de fibra de coco e de 0 a 10\% de resíduo agregante proporcionaram melhores características de crescimento de A. mangium Willd em condições de campo.

Palavras-chave: Acacia mangium, esterco bovino, lodo de esgoto, substratos para produção de mudas

\section{Initial growth of Acacia mangium Willd in soil conditioner formed of coconut fiber and aggregating residue}

\begin{abstract}
The purpose of this work was to evaluate litter layer (soil conditioner) formed of coconut fiber and aggregating residue with different substrate in the initial growth of Acacia mangium Willd plants. A completely randomized block was utilized, with 13 treatments and three replications, in a factorial arrangement $(6 \times 2+1)$, with 6 proportions of fiber of coconut and aggregating residue (100 and $0 \%, 90$ and $10 \%, 80$ and $20 \%, 70$ and $30 \%, 60$ and $40 \%, 50$ and $50 \%$ ), 2 substrates, one containing sewage sludge (subsoil of Red-Yellow Latosol (LVA) plus sewage sludge in the proportion 2:1) and the other with bovine manure (subsoil of Red-Yellow Latosol (LVA) plus decomposed bovine manure in the relation 3:1), and the control as additional treatment, subsoil of Red-Yellow Latosol (LVA). After 173 days of the sowing, the litter layer containing subsoil of LVA and bovine manure was found to be superior to the substrate with subsoil of LVA and sewage sludge in the initial development of A. mangium Willd in height and length of the root. Conditioners containing 90 to $100 \%$ of coconut fiber and of 0 to $10 \%$ of aggregating residue provided better characteristics of growth of $A$. mangium W illd in field conditions.
\end{abstract}

Key words: Acacia mangium, bovine manure, sewage sludge, substrate for production of changes

\footnotetext{
${ }^{1}$ Parte da monografia apresentada pelo primeiro autor ao ICA/UFM G

2 ICA/UFM G, Rua G, 667, Vila Campos, CEP 39403-060. Montes Claros, MG. Fone (38) 9194-8922. E-mail: agroromulo@yahoo.com.br

3 ICA/UFM G, Av. Universitária n. 1000, Bairro Universitário, CEP 39404-006, M ontes Claros, M G. Fone: (38) 2101-7740. E-mail: rsampaio@ufmg.br; dsbrandaojr@ufmg.br; larnaldo@ufmg.br

${ }^{4}$ Departamento de Agronomia/Fitotecnia/U FLA, Rua José Rosa Botelho 225, Vila São Francisco, CEP 37000-000 Lavras, M G. Fone: (35) 9843-8536. E-mail: humbertofu@yahoo.com.br
} 


\section{INTRODUÇÃO}

Grandes esforços são empreendidos às questões que envolvam o meio ambiente, principalmente àquelas associadas à degradação dos solos, causada em decorrência de manejos inadequados (Modesto et al., 2009), oriundos de ações antrópicas. Neste sentido, estudar alternativas de intervenção técnica para acelerar o processo de recomposição vegetal em curto prazo, como o uso de coberturas vegetais (Rodrigues et al., 2007), semeadura direta com espécies arbóreas (Ferreira et al., 2007) e aplicação de adubos orgânicos (Campos \& Alves 2008; Kitamura et al., 2008) é realmente necessário. A recuperação de áreas degradadas ou áreas muito erodidas, das quais se retirou o solo, assim como áreas pedregosas e de mineração, possui uma abordagem de estudos que precisa ser aprofundada, a fim de conter ou restaurar tais problemas.

A produção de mudas de qualidade para a recuperação de solos é um dos fatores a ser considerado visto que a escolha de um bom substrato faz com que as mudas, principalmente na etapa inicial, tenham capacidade de resistir às variadas condições adversas presentes nos locais em que é feito o plantio, razão por que novas alternativas de substratos devem ser testadas para a revegetação de áreas.

Uma espécie que merece destaque em relação à recuperação de solos degradados é a Acacia mangium Willd, pois apresenta rápido crescimento e rusticidade, boa adaptabilidade às condições adversas de solo e clima, além de excelente capacidade de fixação biológica de nitrogênio e de produção de biomassa.

De acordo com Schimitz et al. (2002) a crescente utilização de compostos orgânicos como substrato na fase de obtenção de mudas reflete a necessidade de práticas agrícolas sustentáveis que minimizem o impacto ambiental, sendo fundamental que se avaliem os substratos adequados ao desenvolvimento de cada cultura. $\mathrm{O}$ aproveitamento da casca de coco verde é viável por serem suas fibras quase inertes e terem alta porosidade; além do mais, a facilidade de produção, o baixo custo e a alta disponibilidade, são outras vantagens adicionais apresentadas por esse tipo de substrato.

A fibra da casca do coco verde, resultado do processamento do coco, pode ser importante na produção de substratos de boa qualidade para a produção de mudas ou em cultivos sem o uso do solo. As boas propriedades físicas da fibra de coco, a não reação com os nutrientes da adubação, sua longa durabilidade sem alteração das características físicas, a abundância da matéria-prima e o baixo custo para o produtor, fazem da fibra de coco verde um substrato de excelente uso para a produção de mudas (Carrijo et al., 2002).

As mantas e telas utilizadas com sucesso na recuperação de áreas degradadas têm lenta decomposição, protegem o solo, diminuindo a evaporação, aumentando a retenção de umidade, protegem e aumentam a atividade microbiana do solo e, consequentemente, criam as condições favoráveis ao desenvolvimento vegetal. $\mathrm{O}$ sistema de telas e mantas biodegradáveis tem a vantagem de proporcionar a rápida recuperação do solo e a um baixo custo, se comparado com outros sistemas; tem, ainda, a vantagem de, ao ser incorporado ao terreno com o passar do tempo, diminuir o impacto gerado sobre o meio ambiente. Pode-se salientar, também, os ganhos estéticos para a paisagem logo após sua instalação. As mantas também podem trazer as sementes de gramíneas incorporadas às fibras, as quais germinarão tão logo sejam fixadas no solo e regadas regularmente. Existem ainda redes orgânicas tecidas com fibra de coco verde em cujas malhas é feito o plantio da espécie vegetal desejada (Vallejo, 2005). Holanda et al. (2008) salientam que o uso de materiais que se degradam gradativamente, incluindo-se o geotêxtil fotodegradável composto de $100 \%$ de fibra de coco, é interessante, pois possibilita resgatar, com a maior fidelidade possível, o equilíbrio geomorfológico e ecológico de taludes marginais de rio.

O lodo de esgoto e o esterco bovino, por sua vez, são largamente utilizados na agricultura como fertilizantes, em razão de seus elevados teores de matéria orgânica e de nitrogênio. O lodo de esgoto apresenta grande potencial para aproveitamento agrícola e florestal, quer como condicionante das propriedades físicas, químicas e biológicas do solo, quer como fonte de nutrientes para as plantas cultivadas, tendo em vista sua composição química (Mello et al., 1994; Colodro et al., 2007). Nascimento et al. (2004) verificaram que a adição de doses crescentes de lodo de esgoto aumentou os teores de nitrogênio do solo. Sendo assim, a disposição desse resíduo pela carga de nutrientes e matéria orgânica que concentra, pode substituir parcialmente adubos agrícolas, sobretudo nitrogenados (Carneiro et al., 2005).

O importante é que, ao mesmo tempo em que se aproveitam esses resíduos na agricultura, melhorando a qualidade do solo, evitam-se problemas de contaminação ambiental, principalmente do nitrogênio, cujas altas concentrações são nocivas à saúde.

Esse trabalho teve como objetivo avaliar manta (condicionador do solo) formada de fibra de coco e resíduo agregante com diferentes substratos no crescimento inicial de Acacia mangium Willd.

\section{MATERIAL E MÉTODOS}

O experimento foi realizado em campo e no Laboratório de Análise de Sementes do Instituto de Ciências Agrárias (LAS/ ICA - UFMG) entre os meses de outubro de 2007 a março de 2008, durante operíodo de 173 dias.

O delineamento experimental utilizado no estudo de emergência da Acacia mangium Willd foi o de blocos casualizados, com 13 tratamentos e três repetições, distribuídos em esquema fatorial $(6 \times 2+1)$, correspondendo a 6 proporções de fibra de coco e resíduo agregante (100 e $0 \%$, 90 e $10 \%, 80$ e $20 \%, 70$ e $30 \%, 60$ e $40 \%$, 50 e $50 \%$ ), 2 substratos contendo lodo de esgoto (terra de subsolo de Latossolo Vermelho-Amarelo + lodo de esgoto na proporção 2:1) e esterco bovino curtido (terra de subsolo de Latossolo Vermelho-Amarelo + esterco bovino curtido na relação 3:1), e a testemunha como tratamento adicional (terra de subsolo de Latossolo Vermelho-Amarelo). Os substratos foram acrescidos na superfície das "mantas", formando uma camada para que fosse efetuado o semeio das sementes de A. mangium Willd. 
O lodo de esgoto utilizado como substrato foi o desidratado, coletado na Estação de Tratamento de Esgoto - ETE, no Município de Juramento, MG, operada pela COPASA - MG. Foram feitas análises laboratoriais para determinação das características químicas e físicas das amostras de lodo de esgoto não higienizado seguindo-se metodologias preconizadas por Tedesco et al. (1995): $\mathrm{pH}$ em $\mathrm{H}_{2} \mathrm{O}(4,8)$; matéria orgânica (16,20 $\left.\mathrm{g} \mathrm{kg}^{-1}\right)$; umidade a $65^{\circ} \mathrm{C}(6,0)$; carbono $(9,42 \%)$ e nitrogênio $(2,4 \%)$. As outras fontes de materiais orgânicos utilizados para a composição dos substratos foram o esterco bovino, proveniente do estábulo do setor de Zootecnia, pertencente ao Instituto de Ciências Agrárias da Universidade Federal de Minas Gerais (ICA/UFMG) e a terra de subsolo (Latossolo Vermelho Amarelo) coletado em uma área degradada localizada no mesmo Instituto. A terra de subsolo apresentou as seguintes características químicas e físicas (EMBRAPA, 1997): $\mathrm{pH}$ em água $=(4,9) ; \mathrm{K}\left(\mathrm{mg} \mathrm{dm}^{-3}\right)=34,3 ; \mathrm{P}\left(\mathrm{mg} \mathrm{dm}^{-3}\right)=24,0 ; \mathrm{Ca}^{2+}\left(\mathrm{mmol}_{\mathrm{c}} \mathrm{dm}^{-}\right.$ $\left.{ }^{3}\right)=2,0 ; \mathrm{Mg}^{2+}\left(\mathrm{mmol}_{\mathrm{c}} \mathrm{dm}^{-3}\right)=1,0 ; \mathrm{Al}^{3+}\left(\mathrm{mmol}_{\mathrm{c}} \mathrm{dm}^{-3}\right)=34,0 ; \mathrm{H}$ $+\mathrm{Al}\left(\mathrm{mmol}_{\mathrm{c}} \mathrm{dm}^{-3}\right)=23,2$; Areia grossa $\left(\mathrm{g} \mathrm{kg}^{-1}\right)=240$; Areia fina $\left(\mathrm{g} \mathrm{kg}^{-1}\right)=580$ e Silte $\left(\mathrm{g} \mathrm{kg}^{-1}\right)=40$.

\section{Perfil da qualidade das sementes utilizadas no experimento}

Para obtenção das sementes de Acacia mangium Willd, coletaram-se frutos recém-abertos, oriundos de árvores de bom estado vegetativo, livre de doenças e pragas, localizadas no Instituto de Ciências Agrárias da UFMG, nos meses de setembro a outubro de 2007.

Após as coletas as sementes foram secadas à sombra e em seguida caracterizadas quanto à qualidade física, grau de umidade e massa de mil sementes, e fisiológica, germinação $(\%)$ e vigor $-1^{a}$ contagem (\%), Índice de velocidade de germinação e, posteriormente, utilizadas para a produção das mudas.

\section{Qualidade física}

Grau de umidade (\%): $\mathrm{O}$ grau de umidade das sementes foi determinado pelo método da estufa a $105^{\circ} \mathrm{C} \pm 3{ }^{\circ} \mathrm{C}$, por 24 h, utilizando-se 4 subamostras de 50 sementes colocadas em cápsulas de alumínio, conforme prescrições das Regras de Análises de Sementes (Brasil, 1992).

Massa de 1.000 sementes: Foi determinada a massa de oito subamostras de 100 sementes em balança de precisão com o número de 4 casas decimais (Brasil, 1992).

\section{Qualidade Fisiológica}

Teste de germinação (\%): Realizou-se o teste de germinação com quatro subamostras de 25 sementes. As sementes foram semeadas em caixas plásticas "gerbox" com papel mata-borrão umedecido com água destilada em quantidade de 2,5 vezes a massa do papel; posteriormente, as sementes foram levadas para um germinador modelo Mangelsdorf regulado a temperatura constante de $25{ }^{\circ} \mathrm{C}$. As avaliações foram diárias (protrusão da radícula), uma primeira contagem no $10^{\circ}$ dia e outra contagem final no $18^{\circ}$ dia do início do teste (Brasil, 1992). Consideraram-se germinadas as plântulas normais que apresentavam estruturas essenciais completas, bem desenvolvidas, proporcionais e sadias.
Índice de velocidade de germinação (IVG): Foi determinado anotando-se diariamente o número de sementes com radículas protrundidas durante o teste de germinação e calculado pela fórmula proposta por Maguire (1962). Os números de plântulas normais a partir do dia em que a primeira plântula emergiu, foram contados diariamente até que se tornassem constantes.

\section{Matéria-prima}

\section{Preparo da fibra}

As fibras de coco verde utilizadas no trabalho foram extraídas de cascas de frutos utilizados por pequenas fábricas do mercado local para obter a "água-de-coco".

Para o preparo da fibra utilizou-se uma máquina desintegradora/trituradora de forragem. Depois de seca, a casca do coco, atingindo em torno de $15-20 \%$ de umidade, foi cortada em pedaços para diminuir o embuchamento do sistema de alimentação da trituradora, corte que pode ser substituído por um processo de esmagamento que consiste em fazer de 2 a 4 passadas com um trator de pneus sobre o coco seco sem água dispostos em uma superfície plana do solo. Após o desfibramento fez-se a trituração. Para o processamento da fibra de coco, realizou-se a passagem da casca de coco secado na trituradora, por duas vezes, visto que o uso de peneiras com furos de $3 \mathrm{~mm}$ ou $4 \mathrm{~mm}$ dificulta o processo de trituração devido ao embuchamento. As principais operações para a preparação de substrato a partir da casca de coco verde estão sintetizadas no fluxograma apresentado na Figura 1.

O substrato a partir das fibras de coco não possui os nutrientes essenciais para as plantas. Portanto, é preciso fornecê-los de acordo com as necessidades da espécie a ser cultivada, adicionando-se adubos ao substrato.

As propriedades físico-químicas da fibra de coco variam bastante com a fonte de matéria-prima e do seu processamento. As características químicas e físicas da fibra de coco utilizada na produção do substrato foram: Matéria Orgânica (g $\left.\mathrm{dm}^{-3}\right)=24,77 ; \mathrm{pH}=6,6 ; \mathrm{N}\left(\right.$ dag kg- $\left.^{-1}\right)=0,56 ; \mathrm{P}\left(\right.$ dag kg$\left.^{-1}\right)=$ 0,$15 ; \mathrm{K}\left(\mathrm{dag} \mathrm{kg}^{-1}\right)=1,15 ; \mathrm{Ca}\left(\mathrm{dag} \mathrm{kg}^{-1}\right)=0,45 ; \mathrm{Mg}\left(\mathrm{dag} \mathrm{kg}^{-1}\right)$ $=0,20 ; \mathrm{S}\left(\right.$ dag kg$\left.^{-1}\right)=0,02 ; \mathrm{Zn}\left(\mathrm{mg} \mathrm{kg}^{-1}\right)=12 ; \mathrm{Cu}\left(\mathrm{mg} \mathrm{kg}^{-1}\right)=$ 0,3 ; Mn $\left(\mathrm{mg} \mathrm{kg}^{-1}\right)=14$; Densidade $\left(\mathrm{kg} \mathrm{dm}^{-3}\right)=0,98$ e Capacidade de retenção de água $\left(\mathrm{g} \mathrm{H}_{2} 0 . \mathrm{g}^{-1}\right.$ substrato $)=3$,0; C.E. $\left(\mathrm{mS} \mathrm{cm}^{-3}\right)(1: 5)=2,18$.

\section{Preparo da "manta"}

A "manta" de fibra de coco referida no trabalho tem como componentes basicamente, as fibras de coco (FC) desintegrado mais resíduo agregante (RA), homogeneizado com 2,5 vezes em quantidade de água. A partir das proporções FC/RA ( $\mathrm{m} / \mathrm{m} \%)$ estabelecidas nos tratamentos, esses dois materiais foram colocados em balde de 12 litros e misturados com água. O RA, juntamente com a água, melhora a consistência da "manta". Todo o material homogeneizado foi transferido para uma forma perfurada (Figura 2A), utilizando-se a metade de uma lata de 18 litros com as dimensões de 0,34 x 0,24 x 0,05 m, comprimento, largura e altura, respectivamente, e prensado com o objetivo de melhorar a agregação do condicionador e retirar o excesso 


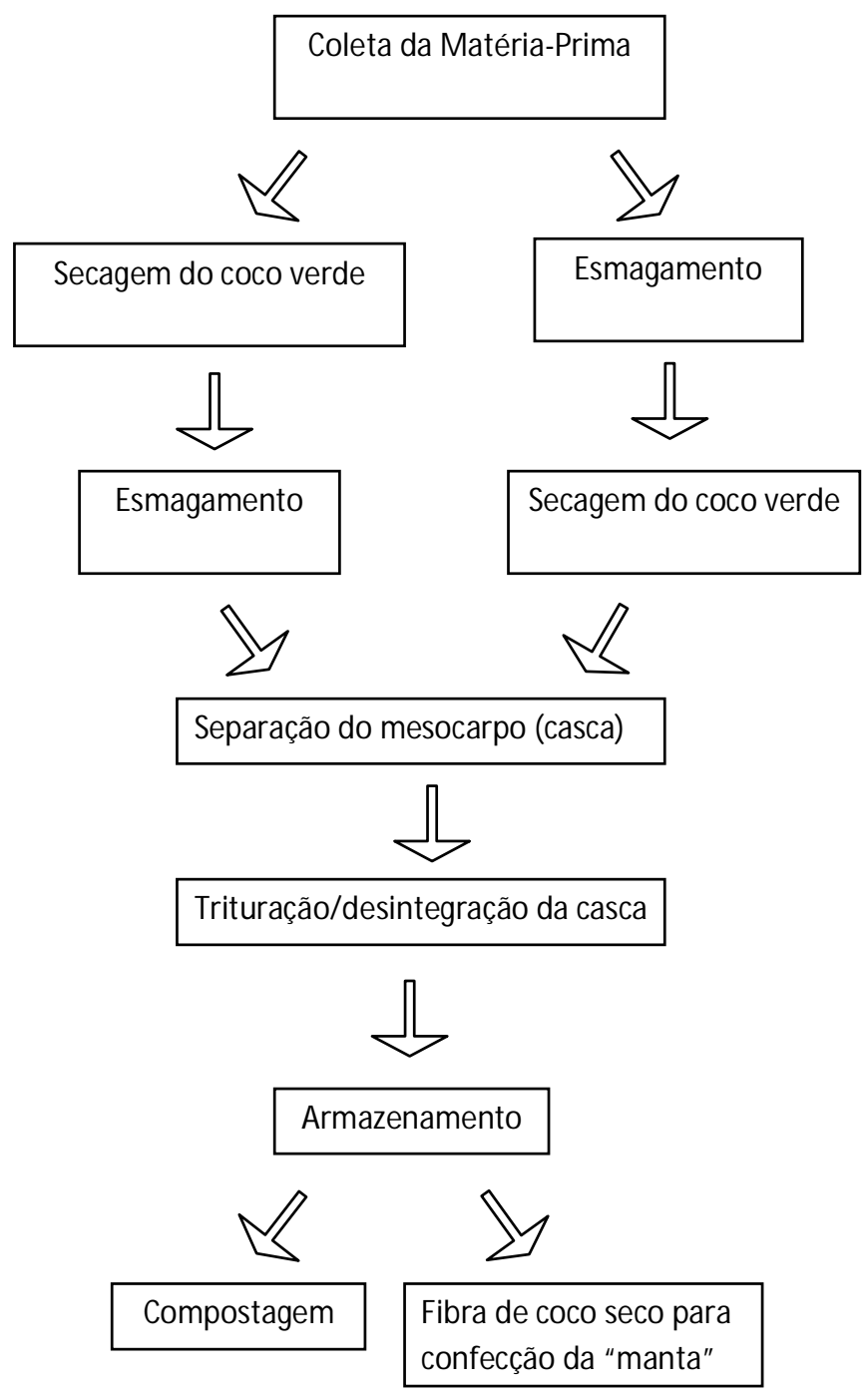

Figura 1. Fluxograma para o aproveitamento da casca de coco verde para a produção de substrato

de água; em seguida, colocou-se a "manta" já confeccionada (Figura 2B) em um ambiente para secagem e assim receber os substratos em sua superfície na qual foi feita a semeadura de A. mangium Willd.

\section{O Experimento no Campo}

\section{Semeadura da Acácia}

As "mantas" com as diferentes frações de fibra de coco e resíduo agregante foram colocadas na superfície do solo, em área localizada no Instituto de Ciências Agrárias da UFMG, dispostas no espaçamento de $1,0 \times 0,5 \mathrm{~m}$. Para evitar perda de substrato das "mantas" pela irrigação ou pela chuva e ainda manter sua umidade, colocou-se em sua superfície uma folha de jornal contendo 25 perfurações, na qual 25 sementes de A. mangium Willd foram colocadas a aproximadamente 2 $\mathrm{cm}$ de profundidade. Para quebra de dormência, as sementes foram submetidas a um tratamento pré-germinativo, que consistiu na imersão em água fervente $\left(100{ }^{\circ} \mathrm{C}\right)$, por 60 segundos (Smiderle et al., 2005). Após semeadura realizaram-se duas irrigações por dia, em razão do período de estiagem, até o mês
A.

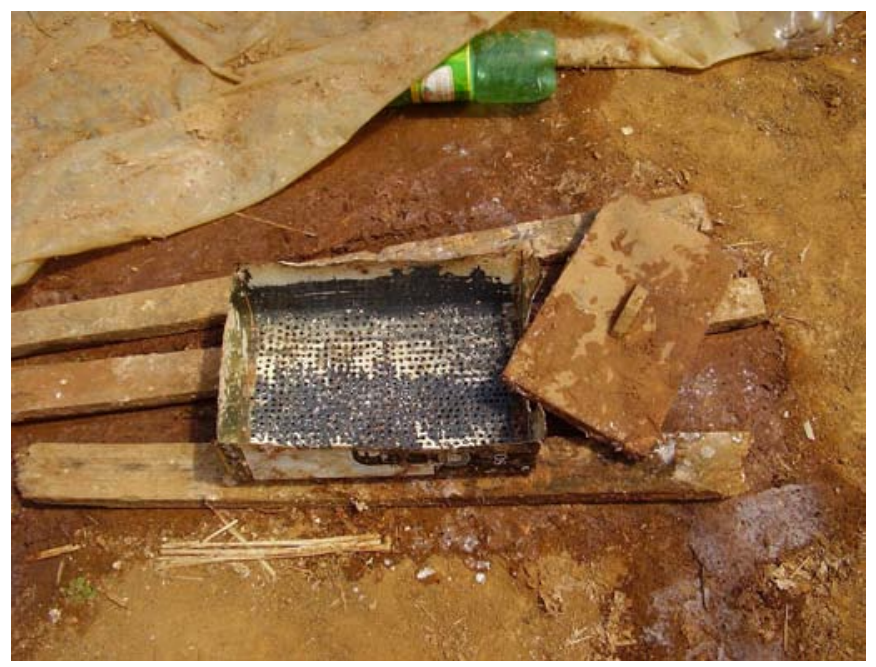

B.

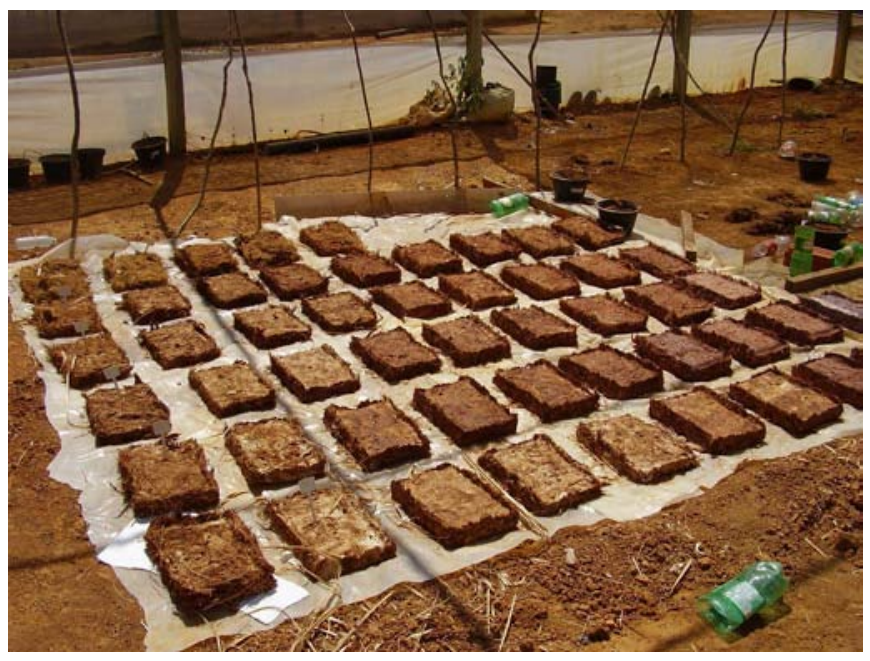

Figura 2. M odelo da forma perfurada (A) e a "manta" pronta (B)

de novembro, conforme dados climáticos apresentados na Tabela 1.

Após estabelecimento das plantas no campo fez-se o desbaste deixando-se apenas 3 plantas por parcela. Obtiveramse os dados analisados apenas de uma planta por parcela,

Tabela 1. Valores acumulados mensais de precipitação total $(\mathrm{mm})$ e médios mensais de temperatura média $\left({ }^{\circ} \mathrm{C}\right)$, insolação total, velocidade do vento $\left(\mathrm{m} \mathrm{s}^{-1}\right)$ e umidade relativa do ar $(\%)$ durante a realização do experimento

\begin{tabular}{cccccc}
\hline Mês & $\begin{array}{c}\text { Precip. total } \\
(\mathbf{m m})\end{array}$ & $\begin{array}{c}\text { Temp. } \\
\text { média (-C) }\end{array}$ & Insol. total & $\begin{array}{c}\text { Vel. do } \\
\left.\text { vento (m s } \mathbf{~}^{-1}\right)\end{array}$ & $\begin{array}{c}\text { Umidade } \\
\text { relativa do } \\
\text { ar (\%) }\end{array}$ \\
\hline Out. $/ 2007$ & 13,3 & 26,0 & 284,8 & 2,3 & 42 \\
Nov./2007 & 72,5 & 26,7 & 221,2 & 2,4 & 52 \\
Dez./2007 & 101,8 & 24,9 & 217,1 & 1,9 & 67 \\
J an./2008 & 135,0 & 24,4 & 133,8 & 1,9 & 67 \\
Fev./2008 & 164,1 & 24,5 & 217,9 & 2,1 & 71 \\
Mar./2008 & 251,6 & 23,5 & 205,5 & - & 78 \\
\hline
\end{tabular}

Fonte: Instituto Nacional de Meteorologia - INMET (2008) 
escolhendo-se aquela com crescimento intermediário ao das outras duas.

No campo, após 173 dias da semeadura as plantas foram avaliadas em:

Teste de emergência (EM) - A porcentagem de emergência foi calculada a partir do número de plântulas emergidas, contadas diariamente, até sua estabilização.

Índice de velocidade de emergência (IVE) - Conduzido em conjunto com o teste de emergência, anotando-se diariamente e no mesmo horário, o número de plântulas que apresentavam folhas visíveis acima do substrato. Ao final do teste e com os dados diários do número de plantas emergidas, calculou-se o índice de velocidade de emergência através da fórmula proposta por Maguire (1962).

O número de plântulas normais emergidas foi contado diariamente a partir do dia em que a primeira plântula emergiu, até que esse número se tornou constante.

Altura final (ALT) (cm) - Com o auxílio de uma trena, mediu-se a altura total da planta a partir do nível do substrato até a ponta da última gema apical.

Diâmetro do caule (DC) (mm) - Mediu-se o diâmetro do caule acima de $3 \mathrm{~cm}$ do nível do substrato com auxílio de um paquímetro de precisão de $0,05 \mathrm{~mm}$;

Número de filódios (NF) por planta - Contou-se o número de filódios simples de todas as plantas da base até o ápice da planta.

Área do filódio (AF) - Mediu-se a área do filódio das plantas através do método de contorno de lâminas foliares desenhadas em papel com massa de áreas conhecidas do mesmo papel.

Matéria seca do caule (MSC), Matéria seca dos filódios (MSF) e Matéria seca das raízes (MSR) (g) - Após a coleta no campo, as plantas de A. mangium foram separadas em caule, filódios e raízes, secadas em estufa a $65^{\circ} \mathrm{C}$ durante 72 horas, até peso constante, e determinação da matéria seca de cada órgão. As raízes foram removidas e lavadas sobre peneiras até a eliminação do solo aderente. Após este período, as diferentes partes das plantas foram pesadas em balança analítica de precisão.

Comprimento da raiz (CR) (cm) - O comprimento das raízes foi medido tomando-se o início da raiz principal até sua extremidade. Para essas medições utilizou-se uma régua milimétrica.

Os dados em porcentagem (x) foram transformados em arco seno $(\mathrm{x} / 100)^{0,5}$. Os dados experimentais foram submetidos a análise de variância e as médias ajustadas a equações de regressões, testando-se os coeficientes até $10 \%$ de probabilidade pelo teste $\mathrm{t}$.

\section{RESULTADOS E DISCUSSÃO}

Os testes de germinação são realizados em laboratório sob condições ideais de temperatura, substrato, teores de umidade para o substrato e outros fatores que forneçam condições para que o lote de sementes possa expressar seu máximo potencial de germinação (Figliolia et al., 1993). Para estimar o potencial de germinação, as sementes de
A. mangium Willd foram submetidas à verificação de suas características fisiológicas e físicas (Tabela 2). Os valores de IVG e EM (Tabela 2), divergiram dos encontrados por Rodrigues et al. (2008) que obtiveram 16,53 e 68\% para IVG e germinação de sementes (Acacia mangium Willd), respectivamente.

Tabela 2. Características fisiológicas e físicas de sementes de Acacia mangium Willd

\begin{tabular}{ccccc}
\hline Espécie & IVG (Índice) & EM (\%) & $\begin{array}{c}\text { Umidade } \\
(\%)\end{array}$ & $\begin{array}{c}\text { Massa de 1000 } \\
\text { sementes (g) }\end{array}$ \\
A. mangium Willd & 3,76 & 87,0 & 5,09 & 14,8 \\
CV (\%) & 15,06 & 13,20 & 18,22 & 1,49 \\
\hline
\end{tabular}

O índice de velocidade de emergência (IVE) e a percentagem de emergência (EM) (Tabela 3 ) foram inferiores aos padrões normais da espécie (Tabela 2) em todos os tratamentos. É provável que tal fato tenha ocorrido em razão das temperaturas mais altas e das baixas umidades relativa do ar, verificadas no início do experimento (Tabela 1). Segundo Marcos Filho (2005), a germinação pode ser afetada por fatores intrínsecos, como vitalidade e viabilidade, longevidade, grau de maturidade, dormência, sanidade e genótipo, e fatores do ambiente, como água, temperatura, oxigênio, luz e promotores químicos. Em trabalhos desenvolvidos com Acacia polyphylla, Araújo Neto et al. (2003) observaram aumento da porcentagem de germinação com o aumento da temperatura até $25^{\circ} \mathrm{C}$, tendendo a decrescer a partir dessa temperatura.

Tabela 3. Contrastes ortogonais comparando-se a testemunha aos tratamentos com manta de fibra de coco e resíduo agregante em relação ao Índice de velocidade de emergência (IVE) e Percentagem de emergência (EM) de A. mangium Willd

\begin{tabular}{|c|c|c|c|}
\hline Contraste & IVE & EM1 & EM2 \\
\hline $\begin{array}{l}\text { Testemunha } \mathrm{x} \\
\text { Mantas }\end{array}$ & $\begin{array}{r}0,47-0,22 \\
=0,25^{*} *\end{array}$ & $\begin{array}{c}0,64-0,41 \\
=0,23^{*} *\end{array}$ & $\begin{array}{c}35,66-15,89 \\
=19,77\end{array}$ \\
\hline
\end{tabular}

Na Tabela 3 se observa que a testemunha apresentou melhores resultados em relação ao IVE e EM, em comparação com as mantas de fibra de coco e resíduo agregante. Os menores valores observados na manta podem ser atribuídos à cobertura do substrato com papel perfurado, o que pode ter impedido maior penetração de luz e umidade no substrato já que a testemunha não foi coberta. Para Croteau \& Zibilske (1998), o solo tratado com resíduo de papel aumenta sua concentração em carbono e imobiliza nitrogênio pelos micro-organismos. Diferente deste experimento, Costa et al. (2007) observaram que o aumento da proporção de fibra de coco em relação ao resíduo compostado de algodão proporcionou maior emergência e índice de velocidade de emergência em mudas de tomateiro. 
Tabela 4. Valores médios ${ }^{1}$ de Índice de velocidade de emergência (IVE) e Percentagem de emergência (EM) de sementes de $A$. mangium Willd em função da proporção de fibra de coco ( $F C$ ) e resíduo agregante (RA) na manta e diferentes

\begin{tabular}{|c|c|c|c|c|c|c|c|c|}
\hline \multirow[b]{2}{*}{ Variedade } & \multirow[b]{2}{*}{ Substrato } & \multicolumn{7}{|c|}{ Proporção de fibra de coco/resíduo agregante } \\
\hline & & $\begin{array}{c}100 \% \mathrm{FC} \\
+ \\
0 \% \mathrm{RA}\end{array}$ & $\begin{array}{c}90 \% \mathrm{FC} \\
+ \\
10 \% \mathrm{RA}\end{array}$ & $\begin{array}{c}80 \% \mathrm{FC} \\
+ \\
20 \% \mathrm{RA}\end{array}$ & $\begin{array}{c}70 \% \mathrm{FC} \\
+ \\
30 \% \mathrm{RA}\end{array}$ & $\begin{array}{c}60 \% \mathrm{FC} \\
+ \\
40 \% \mathrm{RA}\end{array}$ & $\begin{array}{c}50 \% \mathrm{FC} \\
+ \\
50 \% \mathrm{RA}\end{array}$ & Média \\
\hline \multirow{3}{*}{ IVE } & S/lodo & 0,25 & 0,13 & 0,20 & 0,30 & 0,15 & 0,25 & $0,21 \mathrm{a}$ \\
\hline & C/lodo & 0,15 & 0,13 & 0,25 & 0,21 & 0,29 & 0,33 & $0,23 a$ \\
\hline & Média & 0,20 & 0,13 & 0,23 & 0,26 & 0,22 & 0,29 & - \\
\hline \multirow{3}{*}{$\mathrm{EM}^{1}$} & S/lodo & 0,47 & 0,33 & 0,36 & 0,53 & 0,34 & 0,41 & $0,41 a$ \\
\hline & C/lodo & 0,29 & 0,30 & 0,47 & 0,41 & 0,46 & 0,50 & $0,41 \mathrm{a}$ \\
\hline & Média & 0,38 & 0,32 & 0,42 & 0,47 & 0,40 & 0,46 & - \\
\hline
\end{tabular}

${ }^{1}$ Médias transformadas para arco seno $(\mathrm{x} / 100)^{0,5}$; Médias seguidas da mesma letra minúscula na vertical não diferem entre si a $5 \%$ de probabilidade pelo teste $\mathrm{F}$

Não houve interação entre as diferentes proporções de fibra de coco e resíduo agregante e o tipo de adubo orgânico utilizado no substrato para IVE e EM. Na Tabela 4 se observa que a presença de esterco bovino curtido ou de lodo de esgoto no substrato não influenciou o IVE nem a EM das sementes.
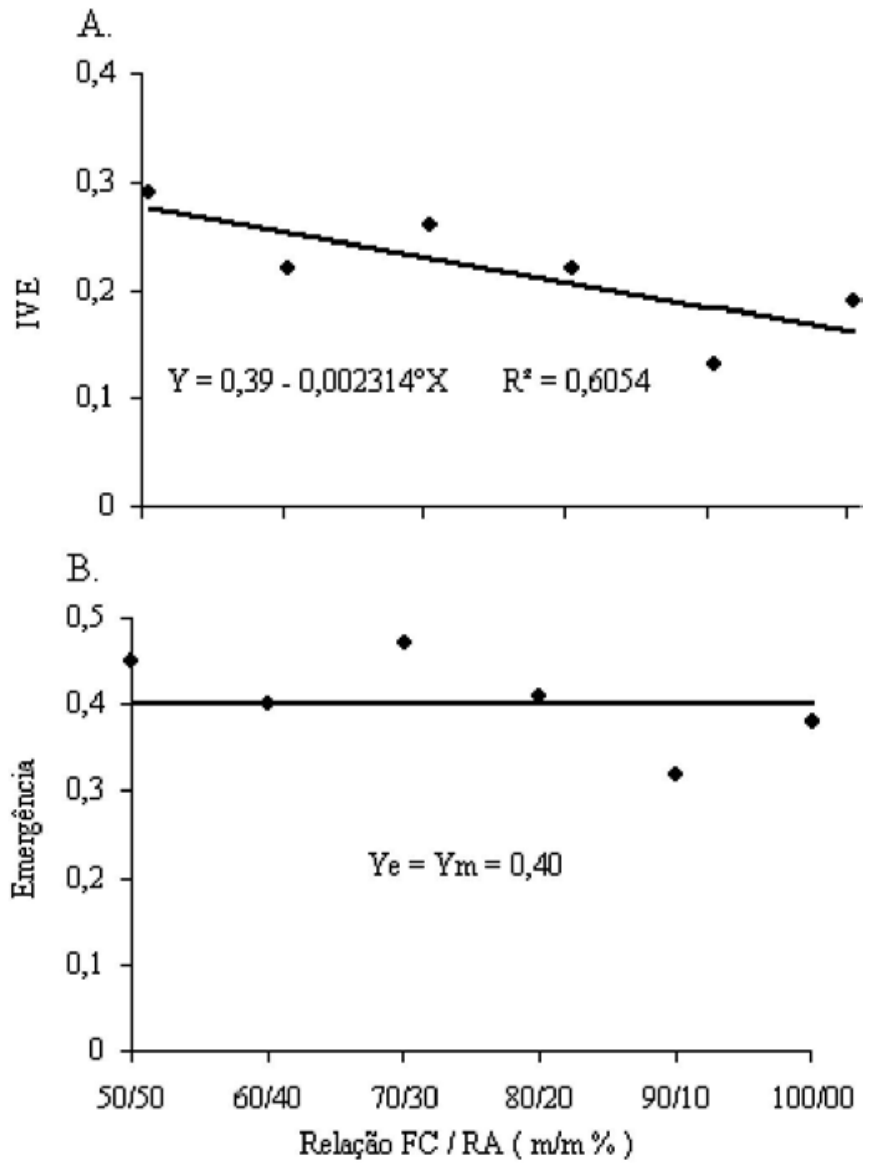

- significativo a $10 \%$ de probabilidade pelo teste $\mathrm{t}$

Figura 3. Índice de velocidade de emergência (A) e percentagem de emergência (B) de plantas de A. mangium Willd em razão da proporção de fibra de coco (FC) e resíduo agregante na manta. Para EM as médias foram transformadas para arco seno $(x / 100)^{0,5}$
Nota-se na Figura 3A, que o IVE diminuiu na medida em que aumentou a proporção de fibra de coco em relação ao resíduo agregante na manta. Para o EM não houve influência das diferentes proporções de fibra de coco e resíduo agregante (Figura 3B).

Tem-se, na Tabela 5, que somente para altura de plantas a testemunha foi superior aos tratamentos contendo manta de fibra de coco e resíduo agregante, não tendo havido diferenças estatísticas para os demais tratamentos. Embora o comprimento da raiz principal da acácia não tenha sido influenciado pela manta, é possível que a presença desta última tenha provocado impedimento físico, restringindo a expansão das raízes secundárias e dificultando uma exploração maior do solo causando menor crescimento da planta. Finger et al. (2000) abordam, em relação às características físicas dos solos, que essas podem ser um dos principais fatores limitantes ao crescimento e produtividade das plantas, sendo que a qualidade física do solo influi não só sobre o crescimento mas também na sanidade e sobrevivência das árvores. Segundo Vale et al. (2006), por não se aprofundarem as raízes exploram menor volume de solo para absorção de água e nutrientes e, em alguns casos, a sustentação da planta também é prejudicada. Os mesmos autores ainda salientam que a boa aeração e a inexistência de impedimento físico possibilitam o crescimento adequado do sistema radicular, de forma que a planta pode absorver água em camadas profundas e explorar maior volume de solo para acessar os nutrientes.

Tabela 5. Contrastes ortogonais comparando-se a testemunha aos tratamentos com manta de fibra de coco e resíduo agregante

\begin{tabular}{lc}
\hline \multicolumn{1}{c}{ Variável } & Contraste \\
\cline { 2 - 3 } Altura da planta $(\mathrm{cm})$ & $88,67-66,95=21,72^{*}$ \\
Diâmetro do caule $(\mathrm{mm})$ & $13,77-10,37=3,40^{\text {ns }}$ \\
Número de filódios & $47,00-46,59=0,41^{\text {ns }}$ \\
Área do filódio $\left(\mathrm{cm}^{2}\right)$ & $3.334,84-2.926,50=408,34^{\text {ns }}$ \\
Matéria seca do caule $(\mathrm{g})$ & $22,33-17,37=4,96^{\mathrm{ns}}$ \\
Matéria seca dos filódios $(\mathrm{g})$ & $33,00-28,00=5,00^{\text {ns }}$ \\
Matéria seca da raiz $(\mathrm{g})$ & $9,00-7,75=1,25^{\mathrm{ns}}$ \\
Comprimento da raiz $(\mathrm{cm})$ & $22,30-23,77=-1,47^{\text {ns }}$ \\
\hline ns, * Não significativo e significativo a $5 \%$ de probabilidade, \\
respectivamente, pelo teste F
\end{tabular}

Não ocorreu interação entre os substratos utilizados e as diferentes proporções de fibra de coco e resíduo agregante na manta, em relação às características de crescimento da planta. Na Tabela 6 se observa que, para altura de plantas e comprimento da raiz principal, o preenchimento da manta com substrato contendo esterco bovino deu melhores resultados do que com lodo de esgoto, possivelmente associado a uma disponibilidade maior de nutrientes, como nitrogênio, fósforo e potássio. Kiehl (1985) destaca que estercos animais têm produzido resultados favoráveis, chegando a se igualarem ou até mesmo superarem os efeitos de fertilizantes minerais. Cunha et al. (2006), comparando substratos com a mesma proporção 

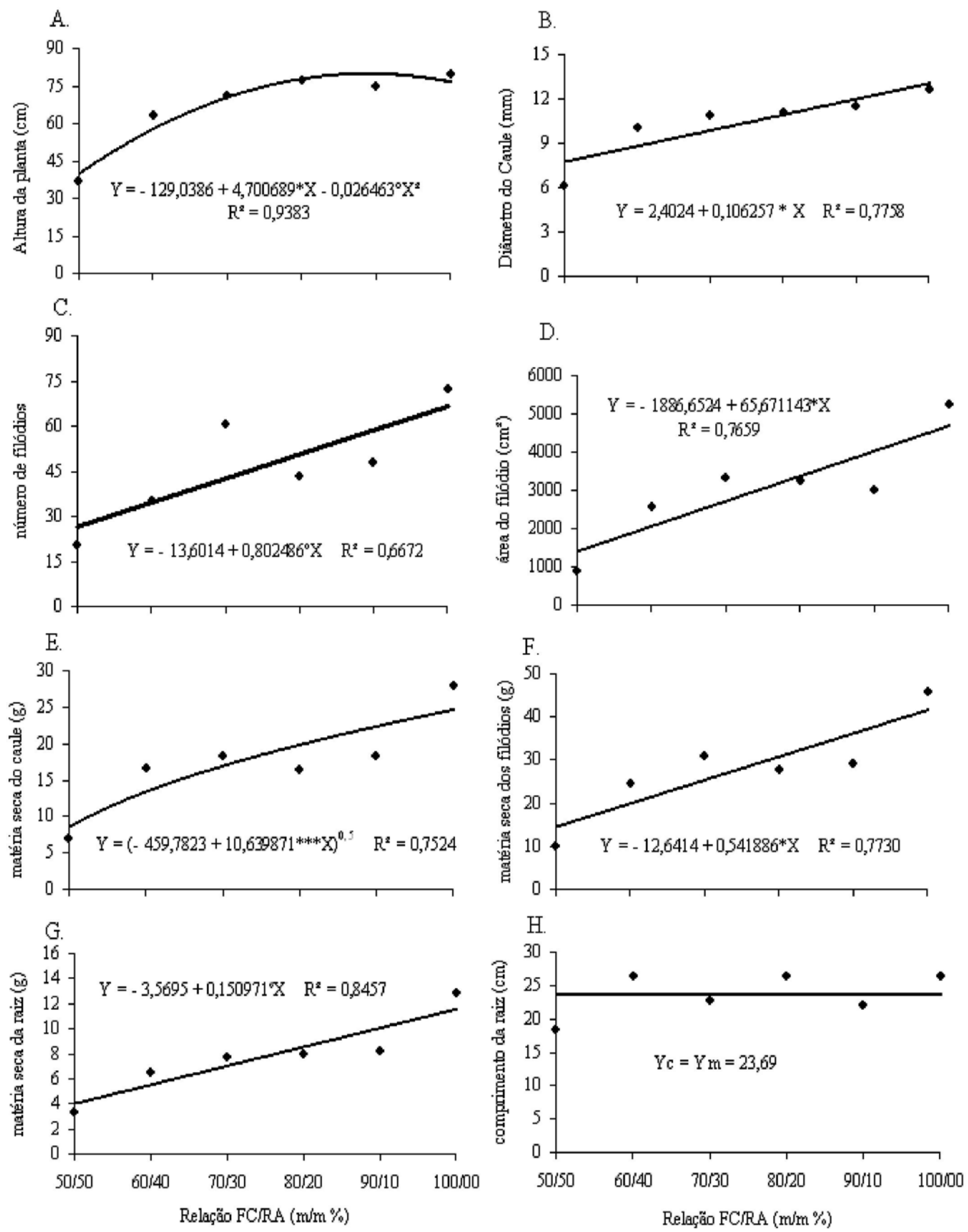

o, $*, * * *$ significativos a 10,5 e $0,1 \%$ de probabilidade, respectivamente, pelo teste $\mathrm{t}$

Figura 4. Altura da planta (A), diâmetro do caule (B), número de filódios (C), área do filódio (D), matéria seca do caule (E), matéria seca dos filódios (F), matéria seca da raiz $(G)$ e comprimento da raiz $(H)$ de plantas de $A$. mangium W illd influenciados pela proporção de fibra de coco (FC) e resíduo agregante (RA) na manta 
Tabela 6. Valores médios de altura da planta (ALT), diâmetro do caule (DC), número de filódios (NF), área dos filódios (AF), matéria seca do caule (MSC), matéria seca dos filódios (MSF), matéria seca da raiz (MSR) e comprimento da raiz (CR) de A. mangium Willd influenciados pelo substrato e pela proporção de fibras de coco $(\mathrm{FC})$ e resíduo agregante (RA) na manta

\begin{tabular}{|c|c|c|c|c|c|c|c|c|}
\hline \multirow[b]{2}{*}{ Variação } & \multirow[b]{2}{*}{ Substrato } & \multicolumn{7}{|c|}{ Relação fibra de coco / resíduo agregante } \\
\hline & & $\begin{array}{l}100 \% \mathrm{FC} \\
+0 \% \mathrm{RA}\end{array}$ & $\begin{array}{c}90 \% \mathrm{FC} \\
+\quad 10 \% \mathrm{RA}\end{array}$ & $\begin{array}{c}80 \% \mathrm{FC} \\
+\quad 20 \% \mathrm{RA}\end{array}$ & $\begin{array}{c}70 \% \mathrm{FC}+30 \% \\
\text { RA }\end{array}$ & $\begin{array}{r}60 \% \mathrm{FC}+ \\
40 \% \mathrm{RA}\end{array}$ & $\begin{array}{c}50 \% \mathrm{FC} \\
+50 \% \mathrm{RA}\end{array}$ & Média* \\
\hline \multirow{3}{*}{$\operatorname{ALT}(\mathrm{cm})$} & Esterco & 95,00 & 69,00 & 48,33 & 64,33 & 85,00 & 78,00 & $73,28 \mathrm{a}$ \\
\hline & Lodo & 91,67 & 54,33 & 41,33 & 57,33 & 87,33 & 31,67 & $60,61 \mathrm{~b}$ \\
\hline & Média & 93,34 & 61,67 & 44,83 & 60,83 & 86,17 & 54,84 & - \\
\hline \multirow{3}{*}{$\mathrm{DC}(\mathrm{mm})$} & Esterco & 16,73 & 10,40 & 7,73 & 8,53 & 11,73 & 12,37 & $11,25 \mathrm{a}$ \\
\hline & Lodo & 14,13 & 9,33 & 5,97 & 8,87 & 12,43 & 6,23 & $9,49 a$ \\
\hline & Média & 15,43 & 9,87 & 6,85 & 8,70 & 12,08 & 9,30 & - \\
\hline \multirow{3}{*}{ NF } & Esterco & 117,67 & 44,00 & 33,33 & 26,67 & 42,67 & 36,67 & $50,17 \mathrm{a}$ \\
\hline & Lodo & 56,33 & 45,67 & 26,33 & 39,67 & 75,67 & 14,33 & $43,00 \mathrm{a}$ \\
\hline & Média & 87,00 & 44,84 & 29,83 & 33,17 & 59,17 & 25,50 & - \\
\hline \multirow{3}{*}{$\mathrm{AF}\left(\mathrm{cm}^{2}\right)$} & Esterco & $7.167,38$ & $2.628,21$ & $1.855,44$ & $1.983,89$ & $3.821,93$ & $3.240,87$ & $3.450,0 \mathrm{a}$ \\
\hline & Lodo & $3.931,75$ & $2.431,67$ & $1.027,47$ & $2.036,01$ & $4.226,59$ & 762,02 & $2.403,0 \mathrm{a}$ \\
\hline & Média & $5.549,57$ & $2.529,94$ & $1.441,46$ & $2.009,95$ & $4.024,26$ & $2.001,45$ & - \\
\hline \multirow{3}{*}{ MSC (g) } & Esterco & 43,67 & 13,67 & 10,00 & 12,00 & 19,00 & 23,33 & $20,28 \mathrm{a}$ \\
\hline & Lodo & 24,67 & 10,33 & 8,00 & 11,67 & 26,00 & 6,00 & $14,45 \mathrm{a}$ \\
\hline & Média & 34,17 & 12,00 & 9,00 & 11,84 & 22,50 & 14,67 & - \\
\hline \multirow{3}{*}{ MSF (g) } & Esterco & 71,33 & 22,67 & 17,00 & 20,33 & 32,33 & 32,00 & $32,61 \mathrm{a}$ \\
\hline & Lodo & 37,67 & 21,67 & 12,00 & 20,67 & 40,33 & 8,00 & $23,39 a$ \\
\hline & Média & 54,50 & 22,17 & 14,50 & 20,50 & 36,33 & 20,00 & - \\
\hline \multirow{3}{*}{ MSR (g) } & Esterco & 19,67 & 7,33 & 4,33 & 6,00 & 8,67 & 8,67 & $9,11 \mathrm{a}$ \\
\hline & Lodo & 10,00 & 5,67 & 3,67 & 6,33 & 9,67 & 3,00 & $6,39 a$ \\
\hline & Média & 14,84 & 6,50 & 4,00 & 6,17 & 9,17 & 5,84 & - \\
\hline \multirow{3}{*}{$\mathrm{CR}(\mathrm{cm})$} & Esterco & 30,30 & 30,70 & 26,00 & 23,20 & 22,10 & 26,80 & $26,52 \mathrm{a}$ \\
\hline & Lodo & 27,80 & 21,00 & 16,90 & 16,10 & 24,50 & 19,80 & $21,02 \mathrm{~b}$ \\
\hline & Média & 29,05 & 25,85 & 21,45 & 19,65 & 23,30 & 23,30 & - \\
\hline
\end{tabular}

*Para cada variável (Var.), médias seguidas da mesma letra minúscula na coluna não diferem significativamente entre si a $5 \%$ de probabilidade pelo teste F

de material orgânico sobre o desenvolvimento de mudas de Acacia sp., obtiveram melhor resultado com o uso de esterco bovino. Garrido et al. (2009) observaram maior tendência do crescimento em altura da mamoneira no qual os tratamentos com adubação orgânica tiveram incrementos significativos quando comparados com o tratamento sem adubos orgânicos. Segundo Filgueira (2000), o esterco bovino eleva a CTC, retém umidade e aumenta a disponibilidade de nutrientes, como o nitrogênio, elemento responsável pelo crescimento da planta.

Verifica-se na Figura $4^{\text {a }}$, que aos 173 dias após a semeadura houve uma relação quadrática entre as proporções de fibra de coco e resíduo agregante em relação à altura da A. mangium Willd, sendo o maior valor estimado de $80 \mathrm{~cm}$, com a proporção de fibra de coco de $89 \%$ e de resíduo agregante de $11 \%$. A análise de regressão para o diâmetro do caule, número de filódios, área dos filódios e matérias secas da raiz, do caule e dos filódios (Figuras 4B, C, D, E, F e G) apresentou comportamento linear sendo a manta contendo $100 \%$ de fibra de coco a que apresentou melhores resultados. O comprimento da raiz, por outro lado, não foi influenciado pelas diferentes proporções de fibra de coco e resíduo agregante da manta. A fibra de coco, extraída do mesocarpo do fruto do coqueiro possui, entre outras características favoráveis, capacidade de reter umidade, boa aeração e drenagem e contém nutrientes importantes ao desenvolvimento das plantas
(Assis et al., 2008). Os incrementos em altura estão relacionados aos acréscimos de matéria orgânica no substrato (Faustino et al., 2005) recomendado, inclusive para a produção de espécie nativa (Mimosa caesalpiniaefolia Benth) e florestal com substratos à base de mistura de pó de coco e fibra de coco (Lacerda et al., 2006; Lopes et al,. 2008). Por outro lado, há relatos de que o não suprimento de nutrientes pela fibra de coco para as plantas possivelmente, é devido, à sua lenta decomposição e liberação de nutrientes (Costa et al., 2007).

\section{CONCLUSÕES}

1. O índice de velocidade de emergência, a percentagem de emergência e a altura da planta da testemunha, foram superiores aos dos tratamentos com manta.

2. O substrato contendo três partes de terra de subsolo de Latossolo Vermelho-Amarelo e uma parte de esterco bovino curtido, foi superior ao substrato contendo duas partes de terra de subsolo de Latossolo VermelhoAmarelo e uma parte de lodo de esgoto em altura da planta e comprimento da raiz de Acacia mangium Willd.

3. Mantas contendo aproximadamente de 90 a $100 \%$ de fibra de coco e de 0 a $10 \%$ de resíduo agregante são as que proporcionam melhores características de crescimento de Acacia mangium Willd em condições de campo. 


\section{LITERATURA CITADA}

Araújo Neto, J. C.; Aguiar, I. B.; Ferreira, V. M. Efeito da temperatura e da luz na germinação de sementes de Acacia polyphylla DC. Revista Brasileira de Botânica, v.26, n.2, p.249256, 2003.

Assis, A. M.; Faria, R. T.; Unemoto, L. K.; Colombo, L. A. Cultivo de Oncidium baueri Lindley (Orchidaceae) em substratos a base de coco. Ciência e Agrotecnologia, v.32, n.3, p.981-985, 2008.

Brasil. Ministério da Agricultura e da Reforma Agrária. Regras para análise de sementes. Brasília: Coordenação de Laboratório Vegetal/Departamento Nacional de Defesa Vegetal, 1992. $365 \mathrm{p}$.

Campos, F. S.; Alves, M. C. Uso de lodo de esgoto na reestruturação de solo degradado. Revista Brasileira de Ciência do Solo, v.32, n.4, p.1389-1397, 2008.

Carneiro, C.; Sottomaior, A. P.; Andreoli, C. V. Dinâmica de nitrogênio em lodo de esgoto sob condições de estocagem. Revista Brasileira de Ciência do Solo, v.29, n.6, p.987-994. 2005.

Carrijo, O. A.; Liz, R. S.; Makishima, N. Fibra da casca do coco verde como substrato agrícola. Horticultura Brasileira, v.20, n.4, 2, p.533-535, 2002.

Colodro, G.; Espíndola, C. R.; Cassiolato, A. M. R.; Alves, M. C. Atividade microbiana em Latossolo degradado tratado com lodo de esgoto. Revista Brasileira de Engenharia Agrícola e Ambiental, v.11, n.2, p.195-198, 2007.

Costa, C. A.; Ramos, S. J.; Sampaio, R. A.; Guilherme, D. O.; Fernandes, L. A. Fibra de coco e resíduo de algodão para substrato de mudas de tomateiro. Horticultura Brasileira, v.25, n.3, p.387-391. 2007.

Croteau, G. A.; Zibilske, L. M. Influence of papermill processing residuals on saprophytic growth and disease caused by Rhizoctonia solani. Apllied soil ecology, v.10, n.1,2. p.103-105. 1998.

Cunha, A. M.; Cunha, G. M.; Sarmento, R. A.; Cunha, G. M.; Amaral, J. F. T. Efeito de diferentes substratos sobre o desenvolvimento de mudas de Acacia sp. Revista Árvore, v.30, n.2, p.207-214, 2006.

EMBRAPA - Empresa Brasileira de Pesquisa Agropecuária. Serviço Nacional de Levantamento e Conservação do Solo. Manual de métodos de análise de solo. Rio de Janeiro: Ministério da Agricultura, 1997. 212p.

Faustino, R.; Kato, M. T.; Florêncio, L.; Gavazza, S. Lodo de esgoto como substrato para produção de mudas de Senna siamea Lam. Revista Brasileira de Engenharia Agrícola e Ambiental, v.9, p.278-282. 2005.

Ferreira, R. A.; Davide, A. C.; Bearzoti, E.; Motta, M. S. Semeadura direta com espécies arbóreas para recuperação de ecossistemas florestais. Cerne, v.13, n.3, p.271-279. 2007.

Figliolia, M. B.; Oliveira, E. C.; Piña Rodrigues, F. C. M. Análises de sementes. In: Aguiar, I. B.; Piña Rodrigues, F. C. M.; Figliolia, M. B. (coord.) Sementes florestais tropicais. Brasília: ABRATES, 1993. cap. 4, p.137-174.

Filgueira, F. A. R. Manual de olericultura: Agrotecnologia moderna na produção e comercialização de hortaliças. 2.ed. Viçosa: UFV, 2000. 402p.
Finger, C. A. G.; Schumacher, M. V. Schneider, P. R. Hoppe, J. M. Influência da camada de impedimento no solo sobre o crescimento de Eucalyptus grandis Hill ex Maiden. Ciência Florestal, v.6, n.1, p.137-146. 2000.

Garrido, M. S.; Menezes, R. S. C.; Sampaio, E. V. S. B.; Marques, T. R. R. Crescimento e absorção de nutrientes pelo algodoeiro e pela mamoneira adubados com gliricídia e esterco. Revista Brasileira de Engenharia Agrícola e Ambiental, v.13, n.5, p.531-536, 2009.

Holanda, F. S. R.; Rocha, I. P.; Oliveira, V. S. Estabilização de taludes marginais com técnicas de bioengenharia de solos no Baixo São Francisco. Revista Brasileira de Engenharia Agrícola e Ambiental, v.12, n.6, p.570-575. 2008.

Kiehl, J. E. Fertilizantes orgânicos. Piracicaba: Agronômica Ceres, 1985. 492p.

Kitamura, A. E.; Alves, M. C.; Suzuki, L. G. A. S.; Gonzalez, A. P. Recuperação de um solo degradado com a aplicação de adubos verdes e lodo de esgoto. Revista Brasileira de Ciência do Solo, v.32, n.1, p.405-416. 2008.

Lacerda, M. R. B.; Passos, M. A. A.; Rodrigues, J. J. V. Características físicas e químicas de substratos à base de pó de coco e resíduo de sisal para produção de mudas de sabiá (Mimosa caesalpiniaefolia Benth). Revista Árvore, v.30, n.2, p.163$170,2006$.

Lopes, J. L. W.; Guerrini, I. A.; Saad, J. C. C.; Silva, M. R. Atributos químicos e físicos de dois substratos para produção de mudas de eucalipto, Cerne, v.14, n.4, p.358-367, 2008.

Maguire, J. D. Speed of germination-aid in selection and evaluation for seedling emergence and vigor. Crop Science, v.2, n.1, p.176-177, 1962.

Marcos Filho, J. D. Fisiologia de sementes de plantas cultivadas. Piracicaba: FEALQ, 2005. 495p.

Mello, W. J.; Marques, M. O.; Santiago, G.; Chelli, R. A.; Leite, S. A. S. Efeito de doses crescentes de lodo de esgoto sobre frações da matéria orgânica e CTC de um Latossolo cultivado com cana-de-açúcar. Revista Brasileira de Ciência do Solo, v.18, n.3, p.449-455, 1994.

Modesto, P. T.; Scabora, M. H.; Colodro, G.; Maltoni, K. L.; Cassiolato, A. M. R. Alterações em algumas propriedades de um Latossolo degradado com uso de lodo de esgoto e resíduos orgânicos. Revista Brasileira de Ciência do Solo, v.33, n.5, p.1489-1498. 2009.

Nascimento, C. W. A.; Barros, D. A. S; Melo, E. E. C.; Oliveira, A. B. Alterações químicas em solos e crescimento de milho e feijoeiro após aplicação de lodo de esgoto. Revista Brasileira de Ciência do Solo, v.28, n.2, p.385-392. 2004.

Rodrigues, A. P. D. C.; Kohl, M. C.; Pedrinho, D. R.; Arias, E. R. A.; Favero, S. Tratamentos para superar a dormência de sementes de Acacia mangium Willd. Acta Scientiarum Agronomy, v.30, n.2, p.279-283, 2008.

Rodrigues, G. B.; Maltoni, K. L.; Cassiolato, A. M. R. Dinâmica da regeneração do subsolo de áreas degradadas dentro do bioma Cerrado. Revista Brasileira de Engenharia Agrícola e Ambiental, v.11, n.1, p.73-80. 2007.

Schmitz, J. A. K.; Souza, P. V. D.; Kampf, A. N. Propriedades químicas e físicas de substratos de origem mineral e orgânica para o cultivo de mudas em recipientes. Ciência Rural, v.32, p.937944, 2002. 
Smiderle, O. J.; Mourão Júnior, M.; Sousa, R. C. P. Tratamentos pré-germinativos em sementes de acácia. Revista Brasileira de Sementes, v.27, n.1, p.78-85, 2005.

Tedesco, M. J.; Gianello, C.; Bissani, C.A.; Bohnen, H.; Volkweiss, S. J. Análise de solo, plantas e outros materiais. 2.ed., Porto Alegre: Departamento de Solos/UFRGS. 1995. 174p. Boletim Técnico, 5.
Vale, L. S.; Severino, L. S.; Beltrão, N. E. de M. Crescimento do pinhão manso em solo compactado. In: Congresso da Rede Brasileira de tecnologia do biodiesel, 1, 2006, Brasília. Anais... Brasília: IBPS. Anais... 2006. p.78-81.

Vallejo, S. Agricultura e pecuária. Sistema Brasileiro de Respostas Técnicas. Rio de Janeiro, Brasil. 2005. www.sbrt.ibict.br/ upload/sbrt709.pdf. 10 Jul. 2008. 